Licença CC BY: Artigo distribuído sob os termos Creative Commons, permite uso e distribuição irrestrita em qualquer meio desde que o autor credite a fonte original.

\section{A HOSPITALIDADE NO UNIVERSO DO TRANSPORTE AÉREO DOMÉSTICO BRASILEIRO}

\author{
HOSPITALITY IN THE BRAZILIAN DOMESTIC AIR TRANSPORT \\ INDUSTRY \\ HOSPITALIDAD EN EL UNIVERSO DEL TRANSPORTE AÉREO \\ NACIONAL BRASILEÑO
}

\author{
ALEXANDRE FARO KAPERAVICZUS' 1 \\ AIRTON JOSÉ CAVENAGHI ${ }^{1}$ \\ PAULO SÉRGIO GONÇALVES DE OLIVEIRA' ${ }^{1}$
}

'UNIVERSIDADE ANHEMBI MORUMBI, SÃO PAULO, SÃO PAULO, BRASIL

RESUMO: Conhecer a forma como os passageiros vivenciam a hospitalidade a bordo das aeronaves que voam no mercado aéreo doméstico brasileiro permite identificar os fatores que são valorizados pelos passageiros e que podem se tornar um diferencial competitivo no disputado mercado da aviação. Dentro do universo da hospitalidade na aviação, a presente pesquisa tem como objetivo estudar a forma como os passageiros percebem a hospitalidade a bordo das aeronaves do transporte aéreo doméstico brasileiro. O estudo é de natureza mista, compreendendo fase qualitativa, com revisão bibliográfica; e fase quantitativa, com o desenvolvimento de instrumento de coleta de dados e a análise de 1.163 questionários, tendo se utilizado como ferramentas de análise os softwares SPSS e SmartPLS. Os resultados alcançados permitem concluir que, na visão dos passageiros, a hospitalidade é percebida a bordo das aeronaves, abrangendo um conjunto de 19 itens que podem ser explicados usando-se 5 fatores que foram denominados "atrativos", "atendimento", "bem-estar", "lowcost" e "higiene" que, submetidos à análise decorrente das hipóteses geradas, permitiu concluir que no Brasil não existem empresas genuinamente "low-cost", tendo em vista que a redução no conforto a bordo das aeronaves não traz a consequente redução de preços esperada.

PALAVRAS-CHAVE: Hospitalidade; Passageiros; Aviação.

\footnotetext{
Alexandre Professor da Pós-Graduação em Direito Aeronáutico da Universidade Anhembi Morumbi, São Paulo, São Paulo, Brasil. Doutor em Hospitalidade pela Universidade Anhembi Morumbi, São Paulo, São Paulo, Brasil. E-mail: farokape@gmail.com. Orcid: 0000-0003-0819-0745

Airton Professor Pesquisador na Universidade Anhembi Morumbi, São Paulo, São Paulo, Brasil. Doutor em História Social pela Universidade de São Paulo, São Paulo, São Paulo, Brasil. E-mail: acavenaghi@gmail. com. Orcid: 0000-0002-1084-8158

Paulo Sérgio Professor e Pesquisador do Programa de Pós-Graduação em Hospitalidade (Mestrado e Doutorado) e do Mestrado Profissional de Gestão de Alimentos e Bebidas da Universidade Anhembi Morumbi, São Paulo, São Paulo, Brasil. Doutorado em Engenharia de Produção, pela Universidade Metodista de Piracicaba, Piracicaba, São Paulo, Brasil. E-mail: psgoliveira@hotmail.com. Orcid: 0000-00019122-4904.
} 


\begin{abstract}
Knowing how passengers experience hospitality during Brazilian domestic flights enables us to identify the factors that are most valued by passengers, and that can be used to gain competitive advantage in the highly competitive Brazilian aviation industry. Within the universe of aviation hospitality, this research aims to study how passengers view hospitality during Brazilian domestic flights. This study uses mixed methods, comprising a qualitative phase, with a bibliographic and quantitative review, the development of data collection questionnaire, and analysis of the responses gathered from 1,163 returned questionnaires, using the software programs SPSS and SmartPLS. The results show how hospitality is perceived by passengers during Brazilian domestic flights, based on a set of 19 items that can be grouped into five factors: "attractiveness", "service", "well-being", "low-cost" and "hygiene". Based on the analysis of the generated hypotheses, this study concludes that there are no genuinely "low cost" companies in Brazil, considering that reduced in-flight comfort is not associated with the consequent expected price reduction.
\end{abstract}

KEY WORDS: Hospitality; Passengers; Aviation.

RESUMEN: Saber cómo los pasajeros ven la hospitalidad a bordo de los aviones nacionales brasileños nos permite identificar los factores que los pasajeros valoran y que pueden convertirse en un diferenciador competitivo en el mercado de aviación brasileño en disputa. Dentro del universo de la hospitalidad en la aviación, esta investigación tiene como objetivo estudiar la forma en que los pasajeros ven la hospitalidad a bordo de los aviones de transporte aéreo nacionales de Brasil. El estudio es de naturaleza mixta y comprende una fase cualitativa con una revisión bibliográfica y cuantitativa con el desarrollo del instrumento de recopilación de datos y el análisis de 1.163 cuestionarios, utilizando el software SPSS y SmartPLS. Los resultados muestran que, a juicio de los pasajeros, se percibe la hospitalidad a bordo de los aviones de transporte aéreo nacionales de Brasil, que cubren un conjunto de 19 elementos que pueden explicarse utilizando 5 factores que se denominaron "atractivo", "servicio", "Bienestar", "bajo costo" e "higiene" y que, en general, no hay compañías genuinamente" de bajo costo en Brasil, ya que se reduce la comodidad a bordo del avión sin la reducción de precios.

PALABRAS CLAVE: Hospitalidad; Pasajeros; Aviación.

\title{
INTRODUÇÃO
}

A palavra hospitalidade pode ser vista como um ato relacionado apenas ao ato de hospedar alguém, quando na realidade ela possui um espectro muito mais abrangente, adentrando na qualidade das relações interpessoais entre quem recebe e quem é recebido, em diversas situações do quotidiano.

Dentro dessa visão de anfitrião e hóspede, constata-se que também no mercado da aviação, mais especificamente a bordo das aeronaves, a tripulação sendo responsável pela acolhida, além de desempenhar as funções técnicas relacionadas à segurança, também é responsável por propiciar a sensação de acolhimento e conforto psicológico no interior das aeronaves. É nesse contexto, da relação entre tripulantes e passageiros, que a hospitalidade se faz presente no universo da aviação, suscitando o interesse em entender como essa hospitalidade é vivenciada pelos usuários do transporte aéreo doméstico brasileiro. 
Cabe ressaltar que, no momento em que se constata a acirrada disputa de passageiros, por parte das empresas aéreas, a hospitalidade a bordo ou a sua ausência pode ser o fator que fará a diferença no momento da escolha pelo passageiro. Desta forma, este estudo é de natureza mista, permeando revisão bibliográfica, abordando a hospitalidade na aviação, na sua fase qualitativa, permitindo conhecer o estado da arte das pesquisas relacionadas ao tema. Na sequência, na sua fase quantitativa, por intermédio de pesquisa de campo cujos dados são submetidos à análise fatorial exploratória e confirmatória, respectivamente utilizando os softwares SPSS e SmartPLS, obtêm-se 5 fatores que foram denominados "atrativos", "atendimento", "bem-estar", "low-cost" e "higiene", que traduzem a forma como a hospitalidade a bordo é vivenciada e percebida pelos passageiros.

\section{REVISÃO TEÓRICA}

Com o intuito de situar o leitor no universo da hospitalidade, em especial, no contexto da aviação, passa-se a seguir e conhecer o estado da arte das pesquisas relacionadas ao tema.

Segundo Camargo (2015), a hospitalidade se dá em interstícios, significando dizer que esta é permeada por momentos visivelmente cercados de inospitalidade e até, por que não, de hostilidade. Significa dizer, nas palavras do autor, que hospitalidade, inospitalidade e a hostilidade sempre caminharão juntas. Já Gotman (2001) considera a hospitalidade como o ato de acolher e servir alguém que esteja fora de seu local de domicílio, sendo resumida na relação entre aquele que recebe e aquele que é recebido por alguém. Para Grinover (2002), a palavra hospitalidade pode ser entendida como recepção de hóspedes, visitantes e viajantes, podendo ser simplificada no ato de bem receber. Nesse cenário, os avanços dos estudos científicos demonstram que a hospitalidade também pode se fazer presente no transporte aéreo, havendo estudos em âmbito nacional e internacional nesse sentido. Em âmbito nacional, mais especificamente, na Pós-Graduação Stricto Sensu em Hospitalidade da Universidade Anhembi Morumbi, foram feitas as abordagens descritas no Quadro 1. 
Tur., Visão e Ação, v22, n3, p463-484, Set./Dez. 2020 - Balneário Camboriú, Santa Catarina, Brasil

Quadro 1 - Pesquisas sobre hospitalidade no transporte aéreo no Brasil

\begin{tabular}{|l|c|}
\hline \multicolumn{1}{|c|}{ Abordagem } & \multicolumn{1}{|c|}{ Autor } \\
\hline $\begin{array}{l}\text { Caracterização do processo de capacitação profissional, desenvolvido } \\
\text { por meio da educaça corporativa, dos agentes de aeroporto de uma } \\
\text { empresa aérea que recebeu o nome fictício de Voa Brasil. }\end{array}$ & Félix \\
\hline $\begin{array}{l}\text { Estudo sobre o Aeroporto de Congonhas, abordando a dimensão de } \\
\text { acolhimento dos passageiros. }\end{array}$ & Favorito (2013) \\
\hline $\begin{array}{l}\text { Comparação dos níveis de hospitalidade percebidos a bordo das aeronaves } \\
\text { de uma empresa tradicional e de uma empresa "low-cost". }\end{array}$ & Kaperaviczus (2015) \\
\hline $\begin{array}{l}\text { Análise da forma pela qual a empresa anfitriã atende as necessidades } \\
\text { específicas do viajante da nova classe média na mobilidade corporativa. }\end{array}$ & Goldenberg (2016) \\
\hline $\begin{array}{l}\text { Estudo denominado "Hospitalidade e serviços a bordo de aeronaves: o caso } \\
\text { da Companhia Aérea Azul", que procurou identificar a bordo das aeronaves } \\
\text { da Azul os quatro tempos da hospitalidade definidos por Camargo (2004). }\end{array}$ & Santos (2017) \\
\hline $\begin{array}{l}\text { Pesquisa intitulada "A gestão de serviços em hospitalidade: o papel do } \\
\text { comissário como anfitrião nas empresas aéreas brasileiras", buscando } \\
\text { investigar a real função dos comissários de voo a bordo. }\end{array}$ & Salva (2017) \\
\hline $\begin{array}{l}\text { Estudo denominado "Correio Aéreo Nacional (CAN): a hospitalidade na } \\
\text { integração de populações isoladas", cujo objetivo foi desvelar a dimensão } \\
\text { da hospitalidade na integração de populações isoladas, pelo Correio Aéreo } \\
\text { Nacional (CAN), dos anos 30 aos anos 80. }\end{array}$ & Calçada (2018) \\
\hline
\end{tabular}

Fonte: Autores (2019).

Assim, o que se percebe das pesquisas em âmbito nacional é que a primeira abordagem foi feita no ano de 2006 e a partir daí se intensificaram, demonstrando o interesse dos pesquisadores em aprofundar os estudos relacionados à hospitalidade no contexto da aviação. Também no cenário internacional se identificam pesquisas abordando a hospitalidade a bordo das aeronaves, conforme demonstra o Quadro 2 Quadro 2 - Pesquisas internacionais sobre hospitalidade no transporte aéreo

\begin{tabular}{|c|c|}
\hline Abordagem & Autor \\
\hline $\begin{array}{l}\text { Avaliação da opção de recompra dos passageiros, baseando-se na } \\
\text { qualidade dos serviços a bordo. }\end{array}$ & Chang e Yang (2008) \\
\hline $\begin{array}{l}\text { Identificação dos fatores mais valorizados pelos passageiros nos serviços } \\
\text { oferecidos pelas empresas aéreas iranianas. }\end{array}$ & Nejati, Nejati e Shafaei (2009) \\
\hline $\begin{array}{l}\text { Estudo na Malásia identificando fatores chave na escolha dos clientes nas } \\
\text { companhias aéreas. }\end{array}$ & Yeoh e Chan (2011) \\
\hline $\begin{array}{l}\text { Pesquisa denominada hospitalidade na aviação, fazendo uma } \\
\text { contextualização histórica da hospitalidade a bordo das aeronaves. }\end{array}$ & Nilsson (2012) \\
\hline $\begin{array}{l}\text { Estudo sobre a influência da qualidade do serviço na satisfação dos } \\
\text { passageiros nas companhias aéreas indianas. }\end{array}$ & Archana e Shuba (2012) \\
\hline $\begin{array}{l}\text { Desenvolvimento de construto para se aferir os níveis de hospitalidade } \\
\text { percebidos a bordo das aeronaves na Malásia. }\end{array}$ & Nameghi e Ariffin (2013) \\
\hline $\begin{array}{l}\text { Trabalho que teve como objetivo descobrir a função e o escopo da } \\
\text { hospitalidade na aviação. }\end{array}$ & Motiani, Patil e Borkar (2013) \\
\hline $\begin{array}{l}\text { Estudo sobre os níveis de hospitalidade dos passageiros na vida privada e } \\
\text { suas expectativas de oferta de hospitalidade nas empresas aéreas. }\end{array}$ & Nameghi (2013) \\
\hline $\begin{array}{l}\text { Pesquisa que, por intermédio de modelo de equações estruturadas, aferiu a } \\
\text { satisfação dos passageiros com os serviços a bordo. }\end{array}$ & Suki (2014) \\
\hline $\begin{array}{l}\text { Avaliação da percepção dos serviços em estudo comparativo das } \\
\text { companhias aéreas nos Emirados Árabes Unidos. }\end{array}$ & Massarat e Jha (2014) \\
\hline Estudo que avaliou a satisfação do cliente na Pakistan International Airlines. & Faizan, Bidit e Raffaele (2015) \\
\hline
\end{tabular}

Fonte: Autores (2019). 
Cabe aqui também ressaltar que a primeira pesquisa em âmbito internacional obtida nas pesquisas realizadas data de 2008 , demonstrando uma contemporaneidade no que diz respeito ao interesse de autores nacionais e internacionais, tendo em vista que a primeira pesquisa do gênero identificada no Brasil data de 2006, percebendose a relevância atribuída ao tema hospitalidade na aviação tanto no Brasil como no exterior. De posse desses dados, o objetivo deste trabalho é estudar a forma como os passageiros enxergam a hospitalidade a bordo das aeronaves do transporte aéreo doméstico brasileiro.

\section{METODOLOGIA}

Como primeiro passo metodológico, cabe classificar a pesquisa, que, de acordo com Gil (2010), aborda a hospitalidade na aviação, estando relacionada com a área das Ciências Sociais Aplicadas, tendo em conta que busca a aquisição de novos conhecimentos. Nesse contexto, segundo Creswell (2010), a pesquisa é de natureza mista, pois contempla a abordagem qualitativa com a revisão bibliográfica e a parte quantitativa compreendida pela análise de dados obtidos na pesquisa de campo.

Inicialmente, a pesquisa é qualitativa, pois tem por objetivo detectar conceitoschave ainda não pensados e entender métodos de coletas de dados utilizados por outros pesquisadores (Sampieri, Collado \& Lucio, 2013). Para tanto, foram realizadas pesquisas por intermédio dos portais Google Acadêmico, Banco de Teses da CAPES, Scientific Electronic Library Online (SCIELO), Blackwell Synergy, Cambridge University Press, Oxford University Press e EBSCO host, nos idiomas português, espanhol e inglês, utilizando respectivamente as palavras-chave "hospitalidade na aviação", "hospitalidad en la aviación" e "hospitality in aviation".

A pesquisa de campo se deu por intermédio de instrumento de coleta, desenvolvido pelos autores, baseado no modelo desenvolvido por Nameghi e Ariffin (2013), utilizando-se formulário do Google Forms. No que se refere à amostra, esta foi não probabilística por conveniência, visto que a escolha dos elementos não depende da probabilidade, mas das características da pesquisa (Sampieri, Collado \& Lucio, 2013). Assim, os dados obtidos foram submetidos à análise fatorial exploratória, com o software SPSS, descrevendo a população e propiciando o estabelecimento de hipóteses, testadas na fase explicativa da pesquisa, por meio de modelo de equações estruturais, utilizando o software SmartPLS.

\section{O INSTRUMENTO DE COLETA DE DADOS}

Partindo-se do modelo de Nameghi e Ariffin (2013), aplicado na Malásia, desenvolveu-se um novo instrumento de coleta de dados para se aferir os níveis de hospitalidade percebidos pelos passageiros a bordo das aeronaves do transporte aéreo doméstico brasileiro, consubstanciado no Quadro 3.

"Responda com base em sua experiência com notas de 1 a 5 às afirmações da tabela abaixo conforme segue: 1- Discordo totalmente; 2- Discordo parcialmente; 3- Não concordo e nem discordo; 4- Concordo parcialmente; 5- Concordo totalmente." 


\section{Quadro 3 - Instrumento de Coleta de Dados}

\begin{tabular}{|c|c|c|c|c|c|}
\hline 1- Os tripulantes interagiram com os passageiros de forma respeitosa. & 1 & 2 & 3 & 4 & 5 \\
\hline $\begin{array}{l}\text { 2- Uma bagagem de mão de até } 10 \mathrm{~kg} \text { confere o nível de conforto necessário ao } \\
\text { passageiro. }\end{array}$ & 1 & 2 & 3 & 4 & 5 \\
\hline $\begin{array}{l}\text { 3- Os tripulantes sempre se esforçaram para atender prontamente às solicitações dos } \\
\text { passageiros. }\end{array}$ & 1 & 2 & 3 & 4 & 5 \\
\hline $\begin{array}{l}\text { 4- Uma bagagem de mão gratuita de, no máximo, } 10 \mathrm{Kg} \text { gerou redução no preço pago } \\
\text { pela passagem aérea. }\end{array}$ & 1 & 2 & 3 & 4 & 5 \\
\hline 5- A empresa cumpriu fielmente o horário de decolagem previsto na passagem aérea. & 1 & 2 & 3 & 4 & 5 \\
\hline 6- Os tripulantes receberam os passageiros a bordo de forma gentil. & 1 & 2 & 3 & 4 & 5 \\
\hline $\begin{array}{l}\text { 7- O espaço entre poltronas e o reclino permitido do encosto me possibilitaram repousar } \\
\text { confortavelmente. }\end{array}$ & 1 & 2 & 3 & 4 & 5 \\
\hline $\begin{array}{l}\text { 8- Os tripulantes agradeceram a preferência convidando a voar novamente com a } \\
\text { empresa. }\end{array}$ & 1 & 2 & 3 & 4 & 5 \\
\hline 9- O número de comissários a bordo permitiu atender prontamente os passageiros. & 1 & 2 & 3 & 4 & 5 \\
\hline 10- Os tripulantes se esforçaram por manter conversas informais com os passageiros. & 1 & 2 & 3 & 4 & 5 \\
\hline 11- Considero fundamental o fornecimento de alimentos e bebidas a bordo. & 1 & 2 & 3 & 4 & 5 \\
\hline $\begin{array}{l}\text { 12- O fornecimento de alimentos e bebidas, somente mediante pagamento durante o } \\
\text { voo, reduz o preço da passagem aérea. }\end{array}$ & 1 & 2 & 3 & 4 & 5 \\
\hline $\begin{array}{l}\text { 13- Os tripulantes se esforçaram, de forma incansável, por auxiliar os passageiros em todas } \\
\text { as suas necessidades. }\end{array}$ & 1 & 2 & 3 & 4 & 5 \\
\hline $\begin{array}{l}\text { 14- Considerei satisfatórios os entretenimentos (TV via satélite, internet wireless, filmes) } \\
\text { disponibilizados a bordo da(s) aeronave(s). }\end{array}$ & 1 & 2 & 3 & 4 & 5 \\
\hline 15- O controle de temperatura foi adequado ao meu conforto. & 1 & 2 & 3 & 4 & 5 \\
\hline $\begin{array}{l}\text { 16- Os tripulantes se esforçaram para que os passageiros pudessem repousar } \\
\text { confortavelmente. }\end{array}$ & 1 & 2 & 3 & 4 & 5 \\
\hline 17- A aeronave estava adequadamente limpa. & 1 & 2 & 3 & 4 & 5 \\
\hline 18- Os banheiros estavam adequadamente higienizados. & 1 & 2 & 3 & 4 & 5 \\
\hline 19- A acolhida e a cordialidade influenciam na escolha da empresa aérea. & 1 & 2 & 3 & 4 & 5 \\
\hline 20- A qualidade do serviço de bordo influencia na escolha da empresa aérea. & 1 & 2 & 3 & 4 & 5 \\
\hline 21- O entretenimento a bordo influencia na escolha da empresa aérea. & 1 & 2 & 3 & 4 & 5 \\
\hline 22- A pontualidade influencia na escolha da empresa aérea. & 1 & 2 & 3 & 4 & 5 \\
\hline 23- O conforto influencia na escolha da empresa aérea. & 1 & 2 & 3 & 4 & 5 \\
\hline $\begin{array}{l}\text { 24- O espaço destinado às bagagens de mão no interior das aeronaves é suficiente para } \\
\text { acomodar os pertences de todos os passageiros. }\end{array}$ & 1 & 2 & 3 & 4 & 5 \\
\hline 25- Concordo com o preço cobrado pela alimentação fornecida a bordo das aeronaves. & 1 & 2 & 3 & 4 & 5 \\
\hline 26 - Aprecio a qualidade dos alimentos fornecidos a bordo das aeronaves. & 1 & 2 & 3 & 4 & 5 \\
\hline
\end{tabular}

Fonte: Autores (2019).

Nesse contexto, após a finalização da coleta de dados, foram respondidos 1.163 questionários, sendo que 68 foram descartados, pelo fato de os respondentes não terem voado no transporte aéreo doméstico brasileiro nos últimos 24 meses, restando, portanto, para análise, 1.095 questionários.

\section{RESULTADOS}

Após submeter metade da amostra à análise fatorial exploratória, por intermédio do SPSS, o programa agrupou as respostas em 5 grupos de questões que se interrelacionam e que estão apresentadas na Tabela 1. 
Tabela 1 - Matriz de Fatores Nomeados

\begin{tabular}{|c|c|c|c|c|c|c|}
\hline \multicolumn{7}{|c|}{ Rotated Component Matrix } \\
\hline & & \multicolumn{5}{|c|}{ Component } \\
\hline \multirow{6}{*}{ 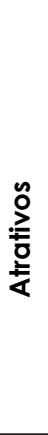 } & & 1 & 2 & 3 & 4 & 5 \\
\hline & $\begin{array}{l}\text { 20- A qualidade do serviço de bordo influencia na escolha } \\
\text { da empresa aérea. }\end{array}$ & .851 & & & & \\
\hline & 23- O conforto influencia na escolha da empresa aérea. & .798 & & & & \\
\hline & $\begin{array}{l}\text { 19- A acolhida e a cordialidade influenciam na escolha da } \\
\text { empresa aérea. }\end{array}$ & .787 & & & & \\
\hline & $\begin{array}{l}\text { 21- O entretenimento a bordo influencia na escolha da } \\
\text { empresa aérea. }\end{array}$ & .734 & & & & \\
\hline & 22- A pontualidade influencia na escolha da empresa aérea. & .721 & & & & \\
\hline \multirow{5}{*}{$\begin{array}{l}\frac{0}{c} \\
\frac{0}{0} \\
\frac{E}{0} \\
\frac{c}{0} \\
\frac{1}{\alpha}\end{array}$} & $\begin{array}{l}\text { 3- Os tripulantes sempre se esforçaram para atender } \\
\text { prontamente às solicitações dos passageiros. }\end{array}$ & & .790 & & & \\
\hline & $\begin{array}{l}\text { 1- Os tripulantes interagiram com os passageiros de forma } \\
\text { respeitosa. }\end{array}$ & & .765 & & & \\
\hline & $\begin{array}{l}\text { 6- Os tripulantes receberam os passageiros a bordo de forma } \\
\text { gentil. }\end{array}$ & & .747 & & & \\
\hline & $\begin{array}{l}\text { 13- Os tripulantes se esforçaram, de forma incansável, por } \\
\text { auxiliar os passageiros em todas as suas necessidades. }\end{array}$ & & .623 & & & \\
\hline & $\begin{array}{l}\text { 9- O número de comissários a bordo permitiu atender } \\
\text { prontamente os passageiros. }\end{array}$ & & .548 & & & \\
\hline \multirow{4}{*}{ 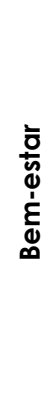 } & $\begin{array}{l}\text { 15- O controle de temperatura foi adequado ao meu } \\
\text { conforto. }\end{array}$ & & & .690 & & \\
\hline & $\begin{array}{l}\text { 14- Considerei satisfatórios os entretenimentos (TV via satélite, } \\
\text { internet wireless, filmes) disponibilizados a bordo da(s) } \\
\text { aeronave(s). }\end{array}$ & & & .647 & & \\
\hline & $\begin{array}{l}\text { 16- Os tripulantes se esforçaram para que os passageiros } \\
\text { pudessem repousar confortavelmente. }\end{array}$ & & & .565 & & \\
\hline & $\begin{array}{l}26 \text { - Aprecio a qualidade dos alimentos fornecidos a bordo } \\
\text { das aeronaves. }\end{array}$ & & & .486 & & \\
\hline \multirow{3}{*}{ 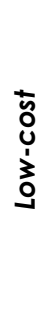 } & $\begin{array}{l}\text { 12- O fornecimento de alimentos e bebidas, somente } \\
\text { mediante pagamento durante o voo, reduz o preço da } \\
\text { passagem aérea. }\end{array}$ & & & & .835 & \\
\hline & $\begin{array}{l}\text { 4- Uma bagagem de mão gratuita de, no máximo, 10Kg } \\
\text { gerou redução no preço pago pela passagem aérea. }\end{array}$ & & & & .771 & \\
\hline & $\begin{array}{l}\text { 25- Concordo com o preço cobrado pela alimentação } \\
\text { fornecida a bordo das aeronaves. }\end{array}$ & & & & 637 & \\
\hline \multirow[t]{2}{*}{ 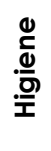 } & 18- Os banheiros estavam adequadamente higienizados. & & & & & .827 \\
\hline & 17- A aeronave estava adequadamente limpa. & & & & & .812 \\
\hline
\end{tabular}

Fonte: Autores (2019).

Este construto explica a forma como a hospitalidade é percebida a bordo das aeronaves brasileiras, na visão dos passageiros, sendo composto por 19 itens que podem ser explicados por 5 fatores que os autores, baseando-se na revisão de 
literatura, denominaram "atrativos", "atendimento", "bem-estar", "low-cost" e "higiene" escalonados na Tabela 1 na sequência de sua importância. Em termos práticos, a análise fatorial exploratória explica a forma como as perguntas se relacionam e conseguem explicar a hospitalidade a bordo das aeronaves, estando a seguir as definições escolhidas pelos autores para cada um dos fatores que se relacionam à hospitalidade a bordo das aeronaves.

Atrativos - Fator que está associado a um conjunto de motivos que levam o passageiro a fazer a escolha pela empresa aérea.

Atendimento - Fator que se relaciona à qualidade das relações interpessoais entre passageiros e tripulantes.

Bem-estar - Fator relacionado a aspectos tangíveis e intangíveis que permitem que o passageiro realize a viagem de forma confortável.

Low-cost - Fator associado ao fornecimento de alimentos e bebidas a bordo somente mediante pagamento e à limitação do volume e do peso das bagagens de mão, fatores que estão normalmente associados à operação "low-cost".

Higiene - Fator associado à sensação de limpeza na cabine de passageiros e nos banheiros.

Assim, a partir da definição destes fatores, tendo como base a revisão de literatura, as respostas apresentadas na pesquisa de campo e as impressões gerais dos autores, foram formuladas hipóteses relacionando os fatores obtidos da análise fatorial exploratória, consubstanciadas na Figura 1.

Figura 1 - Modelo Teórico de Correlações

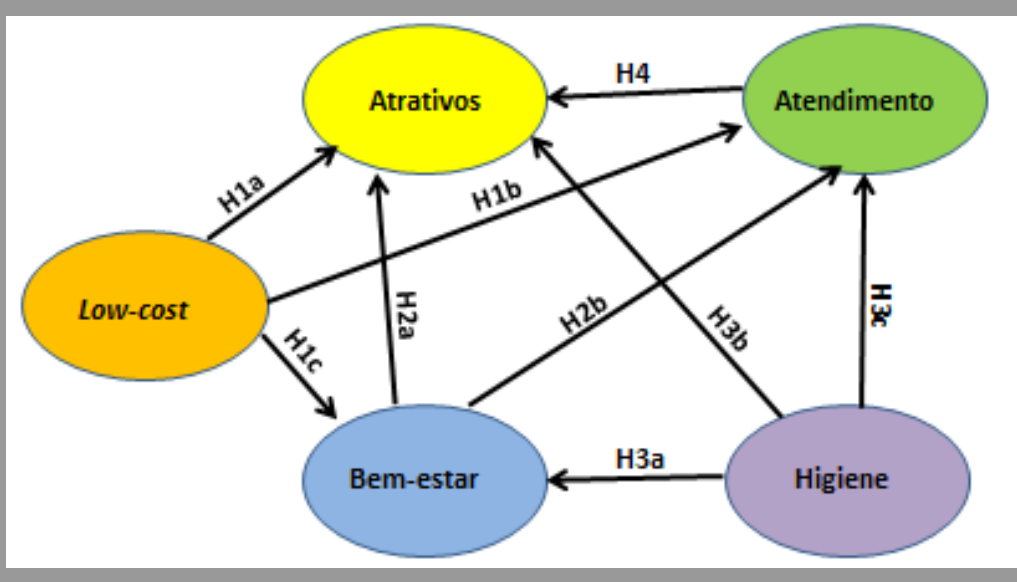

Fonte: Autores (2019).

Desta forma, o fator "low-cost" foi definido como hipótese Hl e, na visão dos autores, exerce influência em "atrativos" ( $\mathrm{Hla}$ ), "atendimento" ( $\mathrm{H} 1 \mathrm{~b})$ e "bem-estar" (Hlc). O fator "bem-estar" foi definido como hipótese H2 e na visão dos autores exerce influência em "atrativos" (H2a) e "atendimento" (H2b). Já o fator "higiene" foi definido como hipótese $\mathrm{H} 3$ e na visão dos autores exerce influência em "bem-estar" (H3a), "atrativos" (H3b) e "atendimento" (H3c). No que se refere ao fator "atendimento", este foi definido como hipótese $\mathrm{H} 4$ e na visão dos autores exerce influência somente no 
fator "atrativos" (H4). Por derradeiro, no que se refere ao fator "atrativos", na visão dos autores, ele não exerce influência em nenhum dos outros fatores, mas é influenciado por todos. A partir deste momento, as hipóteses foram submetidas à prova por intermédio da análise fatorial confirmatória realizada pelo software SmartPLS 3.2.8 e, na sequência, novamente analisadas à luz do referencial teórico e de todo conhecimento gerado no decorrer do estudo. Cabe aqui esclarecer, mais uma vez, que a amostra foi dividida em duas partes para se evitar a ocorrência de viés da análise dos dados coletados.Para tanto, a análise fatorial confirmatória (AFC) foi iniciada por meio das equações estruturais que objetivou testar o modelo teórico. Para facilitar a análise fatorial confirmatória, as variáveis remanescentes do processo foram recodificadas, seguindo o padrão de nomeação apresentado na Tabela 2.

Tabela 2 - Recodificação das Variáveis Remanescentes após AFE

\begin{tabular}{|c|c|c|}
\hline Sequência & Assertivas do Estudo & Recodificada \\
\hline 1 & $\begin{array}{l}\text { 20- A qualidade do serviço de bordo influencia na escolha da empresa } \\
\text { aérea. }\end{array}$ & ATRAT01 \\
\hline 2 & 23- O conforto influencia na escolha da empresa aérea. & ATRAT02 \\
\hline 3 & $\begin{array}{l}\text { 19- A acolhida e a cordialidade influenciam na escolha da empresa } \\
\text { aérea. }\end{array}$ & ATRAT03 \\
\hline 4 & 21- O entretenimento a bordo influencia na escolha da empresa aérea. & ATRAT04 \\
\hline 5 & 22- A pontualidade influencia na escolha da empresa aérea. & ATRAT05 \\
\hline 6 & $\begin{array}{l}\text { 3- Os tripulantes sempre se esforçaram para atender prontamente às } \\
\text { solicitações dos passageiros. }\end{array}$ & ATEND01 \\
\hline 7 & 1- Os tripulantes interagiram com os passageiros de forma respeitosa. & ATEND02 \\
\hline 8 & 6- Os tripulantes receberam os passageiros a bordo de forma gentil. & ATEND03 \\
\hline 9 & $\begin{array}{l}\text { 13- Os tripulantes se esforçaram, de forma incansável, por auxiliar os } \\
\text { passageiros em todas as suas necessidades. }\end{array}$ & ATEND04 \\
\hline 10 & $\begin{array}{l}\text { 9- O número de comissários a bordo permitiu atender prontamente os } \\
\text { passageiros. }\end{array}$ & ATEND05 \\
\hline 11 & 15- O controle de temperatura foi adequado ao meu conforto. & BETRO1 \\
\hline 12 & $\begin{array}{l}\text { 14- Considerei satisfatórios os entretenimentos (TV via satélite, internet } \\
\text { wireless, filmes) disponibilizados a bordo da(s) aeronave(s). }\end{array}$ & BETRO2 \\
\hline 13 & $\begin{array}{l}\text { 16- Os tripulantes se esforçaram para que os passageiros pudessem } \\
\text { repousar confortavelmente. }\end{array}$ & BETR03 \\
\hline 14 & 26 - Aprecio a qualidade dos alimentos fornecidos a bordo das aeronaves. & BETRO4 \\
\hline 15 & $\begin{array}{l}\text { 12- O fornecimento de alimentos e bebidas, somente mediante } \\
\text { pagamento durante o voo, reduz o preço da passagem aérea. }\end{array}$ & LCSTO1 \\
\hline 16 & $\begin{array}{l}\text { 4- Uma bagagem de mão gratuita de, no máximo, } 10 \mathrm{Kg} \text { gerou redução } \\
\text { no preço pago pela passagem aérea. }\end{array}$ & LCSTO2 \\
\hline 17 & $\begin{array}{l}\text { 25- Concordo com o preço cobrado pela alimentação fornecida a } \\
\text { bordo das aeronaves. }\end{array}$ & LCSTO3 \\
\hline 18 & 18- Os banheiros estavam adequadamente higienizados. & HIG01 \\
\hline 19 & 17- A aeronave estava adequadamente limpa. & HIG02 \\
\hline
\end{tabular}

Fonte: Dados da Pesquisa (2019). 
Após a recodificação apresentada na Tabela 2, as variáveis foram submetidas à análise pelo modelo de equações estruturais. Na primeira rodada do modelo, a variável ATEND02=>0,338; na segunda rodada, a variável ATRAT02 $=>0,479$; na terceira rodada, a variável ATRAT05=>0,476; e, finalmente, na quarta rodada, a variável BETR03=>0,471 apresentaram valores abaixo da recomendação de Fornel e Lacker (1981), que é AVE acima de 0,5, sendo eliminadas do modelo. A variável ATEND06=>0,684 também foi eliminada porque o AVE do fator atendimento foi 0,484 , portanto abaixo de 0,5 .

Após a eliminação dessas variáveis, passou-se à análise das cargas cruzadas do modelo, optando-se por mover a variável ATEND04, para o construto "bem-estar", por apresentar cargas muito semelhantes, o que gerou o entendimento de que os respondentes visualizam essa variável da mesma forma, não havendo discriminação nas respostas. A mudança foi efetuada, tendo a variável apresentado cargas cruzadas consistentes. Devido ao fato de possuir cargas semelhantes no construto "bem-estar" e "atendimento", a variável ATEND04 foi movida para o fator "bem-estar", para se verificar se havia um melhor ajuste do modelo, o que acabou ocorrendo e por essa razão a variável foi mantida nesse fator.

Ato contínuo, após se efetuar os ajustes, passou-se à análise da qualidade do modelo, que apresentou os valores apresentados na Tabela 3.

Tabela 3 - Qualidade do Modelo de Equações Estruturais

\begin{tabular}{|l|c|c|c|c|}
\hline & $\begin{array}{c}\text { Alpha de } \\
\text { Cronbach }\end{array}$ & rho_A & $\begin{array}{c}\text { Confiabilidade } \\
\text { Composta }\end{array}$ & $\begin{array}{c}\text { Variância Média } \\
\text { Extraída (AVE) }\end{array}$ \\
\hline Atendimento & 0,648 & 0,666 & 0,810 & 0,589 \\
\hline Atrativos & 0,821 & 0,831 & 0,893 & 0,736 \\
\hline Bem-Estar & 0,654 & 0,699 & 0,811 & 0,594 \\
\hline Higiene & 0,707 & 0,708 & 0,872 & 0,773 \\
\hline Low-cost & 0,637 & 0,665 & 0,805 & 0,583 \\
\hline
\end{tabular}

Fonte: Dados da Pesquisa (2019).

Tendo como base os dados apresentados na Tabela 3, por meio da coluna "Variância média extraída", percebe-se que todos os valores ficaram acima dos recomendados por Fornel e Lacker (1981) e de Hair et al. (2014) para esse critério, que são valores acima de 0,5. Sendo os valores apresentados: Atendimento $=>0,589$, Atrativos $=>0,736$, Bem-Estar $=>0,594$, Higiene $=>0,773$ e Low-cost $=>0,583$.

Utilizando-se novamente a Tabela 3 como base, passou-se ao próximo critério de análise do modelo, tendo como referência as recomendações propostas por Hair et al. (2014) e também de Pestana e Gageiro (2013) para o índice Alpha de Cronbach, que mede a confiabilidade interna do modelo, cujos valores recomendados devem ficar acima de 0,6. Tendo como base os valores da coluna Alpha de Cronbach da Tabela 3, verifica-se que os fatores apresentaram os seguintes valores: Atendimento $=>$ 0,648 , Atrativos $=0,821$, Bem-Estar $=>0,654$, Higiene $=>0,707$ e Low-Cost $=>0,637$, os quais ficam acima do valor recomendado. 
Devido ao fato do Alpha de Cronbach ser sensível ao número de itens existentes na escala, isto pode levar a uma subestimação da consistência, conforme observam Hair et al. (2014), sendo que, por essa razão, recomenda-se que se utilize também a confiabilidade composta do modelo para se aferir a qualidade do mesmo, devendo os valores limites para estudos exploratórios ficar acima de 0,6. Os valores apresentados na Tabela 3 são: Atendimento $=>0,810$, Atrativos $=>0,893$, Bem-Estar $=>0,811$, Higiene $=>0,872$ e Low-Cost $=>0,805$, demonstrando que todos os valores cumprem a recomendação.

Nesse mesmo escopo, passou-se à análise da qualidade do modelo pela análise do Coeficiente de Pearson, que faz a explicação das relações entre os construtos presentes no modelo, seguindo as recomendações propostas por Hair et al. (2014), cujos limites são os seguintes: entre 0 e 0,4 => Fraco; entre 0,4 e 0,7 => moderado; e entre 0,7 e $0,9=>$ forte. Desta forma, os valores encontrados podem ser interpretados da seguinte forma: Atendimento $=$ moderado e Atrativos e Bem-Estar $=$ Fraco.

A Tabela 4 demonstra os valores do indicador SRMR (Standardized Root Mean Square Residual):

Tabela 4 - Medidas de Adequação do Modelo

\begin{tabular}{|c|c|c|}
\hline & Saturated Model & Estimated Model \\
\hline SRMR & 0,075 & 0,076 \\
\hline d_ULS & 0,598 & 0,605 \\
\hline d_G & 0,229 & 0,230 \\
\hline Chi-Square & 765,479 & 767,221 \\
\hline NFI & 0,638 & 0,638 \\
\hline
\end{tabular}

Fonte: Pesquisa (2019)

Para se finalizar a análise da adequação do modelo, utilizou-se o teste de resíduos médios padronizados (Root Mean Square Residual), que é uma medida de adequação do modelo que mede as diferenças entre a matriz de correlações observadas e a matriz de correlações do modelo implícito, o que significa que esse índice reflete a magnitude de tais diferenças, indicando que quanto menor o valor de SRMR, melhor é a adequação (GARSON, 2016). Os valores que demonstram um bom ajuste do modelo devem ficar abaixo de 0,8, segundo Hu e Bentler (1999) e Henseler et al. (2009). Assim, o valor encontrado para o modelo foi de 0,076 , indicando que 0 ajuste do modelo é muito bom. O valor do $X^{2}=>767,221, \mathrm{NFI}=>0,638$.

Tendo sido feitas as análises de qualidade de modelo, passou-se para as análises discriminantes, primeiramente por meio da matriz de cargas cruzadas, apresentadas na Tabela 5. 
Tur., Visão e Ação, v22, n3, p463-484, Set./Dez. 2020 - Balneário Camboriú, Santa Catarina, Brasil

Tabela 5 - Matriz de Cargas Cruzadas

\begin{tabular}{|c|c|c|c|c|c|}
\hline & Atendimento & Atrativos & Bem-Estar & Higiene & Low-cost \\
\hline ATEN01 & 0,845 & 0,120 & 0,536 & 0,256 & 0,211 \\
\hline ATEN03 & 0,756 & 0,121 & 0,447 & 0,249 & 0,149 \\
\hline ATEN04 & 0,582 & 0,193 & 0,840 & 0,300 & 0,239 \\
\hline ATEN05 & 0,693 & 0,110 & 0,383 & 0,316 & 0,145 \\
\hline BETR01 & 0,278 & 0,165 & 0,608 & 0,214 & 0,257 \\
\hline BETR02 & 0,475 & 0,183 & 0,840 & 0,382 & 0,204 \\
\hline ATRAT01 & 0,154 & 0,881 & 0,173 & 0,163 & 0,064 \\
\hline ATRAT03 & 0,142 & 0,866 & 0,236 & 0,176 & 0,097 \\
\hline ATRAT04 & 0,094 & 0,826 & 0,183 & 0,169 & 0,103 \\
\hline HIGN01 & 0,302 & 0,190 & 0,328 & 0,873 & 0,100 \\
\hline HIGN02 & 0,317 & 0,159 & 0,364 & 0,885 & 0,147 \\
\hline LCST01 & 0,162 & 0,034 & 0,233 & 0,103 & 0,839 \\
\hline LCST02 & 0,217 & 0,151 & 0,255 & 0,141 & 0,812 \\
\hline LCST03 & 0,118 & 0,039 & 0,178 & 0,069 & 0,621 \\
\hline
\end{tabular}

Fonte: Dados da Pesquisa (2019).

A Tabela 5 de cargas cruzadas apresenta as cargas das variáveis em seus respectivos construtos, sugerindo que, caso a variável apresente cargas maiores em outros construtos, esse fator sugeriria uma maior identificação desses indicadores com outros construtos. Com esse olhar, ao analisar a Tabela 5, pode-se perceber que todas as cargas fatoriais dos indicadores são maiores nos construtos aos quais foram designados, sugerindo que devem ser mantidos onde estão (HAIR et al., 2014).

A segunda etapa da análise discriminante é determinar a discriminação do modelo por meio do critério de Fornell e Lacker (1981), cujos resultados estão apresentados na Tabela 6.

Tabela 6 - Critério de Fornell e Lacker

\begin{tabular}{|l|c|c|c|c|c|}
\hline & Atendimento & Atrativos & Bem-Estar & Higiene & Low-cost \\
\hline Atendimento & 0,767 & & & & \\
\hline Atrativos & 0,152 & 0,858 & & & \\
\hline Bem-Estar & 0,599 & 0,233 & 0,770 & & \\
\hline Higiene & 0,352 & 0,198 & 0,394 & 0,879 & \\
\hline Low-cost & 0,222 & 0,104 & 0,294 & 0,141 & 0,764 \\
\hline
\end{tabular}

Fonte: Dados da Pesquisa (2019).

De acordo com o critério de Fornell-Larcker (1981), a raiz quadrada de cada constructo deve ser maior que as maiores correlações com qualquer outro construto (CHIN; HENSELER; WANG, 2016; GARSON, 2016; HAIR et al., 2014). Tendo como base os valores encontrados na Tabela 6, apenas o valor de "Low-Cost" possui valores menores que as respectivas correlações, porém devido à proximidade desses valores, optou-se por manter a validade discriminante. 
Para se avaliar a validade discriminante do modelo, optou-se por utilizar o modelo de correlações Heterotrait-Monotrait, demonstrado na Tabela 7.

Tabela 7 - Correlações HTMT (Heterotrait-Monotrait)

\begin{tabular}{|l|r|l|r|l|l|}
\hline & \multicolumn{1}{|l|}{ Atendimento } & Atrativos & \multicolumn{1}{c|}{ Bem-Estar } & Higiene & Low-cost \\
\hline Atendimento & & & & & \\
\hline Atrativos & 0,208 & & & & \\
\hline Bem-Estar & 0,883 & 0,315 & & & \\
\hline Higiene & 0,528 & 0,259 & 0,570 & & \\
\hline Low-cost & 0,335 & 0,134 & 0,467 & 0,203 & \\
\hline
\end{tabular}

Fonte: Dados da Pesquisa (2019).

A Tabela 7 apresenta o modelo Heterotrait-Monotrait, que é a medida da taxa da média geométrica das correlações do heterotrait-heterométodo, dividido pela média das correlações das submatrizes monotrait-monométodo, cujos valores encontrados nas correlações heterotrait devem ser menores que as correlações monotrait, a uma taxa inferior a 1 (Garson, 2016). Henseler, Ringle e Sinkovics (2009) sugerem que os valores devem ser menores que 0,90 para apresentar validade discriminante.

Observando-se a Tabela 7, constata-se que os valores de Heterotrait são menores que orecomendado: Atrativos $=>$ Atendimento $=0,208$, Bem-Estar $=>$ Atendimento $=0,883$, Higiene $=>$ Atendimento $=0,528$, Low-cost $=>$ Atendimento $=0,335$, Bem-Estar $=>$ atrativos $=0,315$, Higiene $=>$ Atrativos $=0,259$, Higiene $=>$ Bem-Estar $=0,570$, Low-Cost $=>$ Atrativos $=$ 0,314, Low-Cost=>Bem-estar = 0,467 e Low-Cost => Higiene = 0,203.

Dando continuidade, passou-se a verificar a validade preditiva do modelo por meio do Indicador de Stone-Geisser, apresentado na Tabela 8.

Tabela 8 - Indicador de Stone-Geisser

\begin{tabular}{|l|l|}
\hline & $\mathbf{Q}^{2}$ \\
\hline Atendimento & 0,208 \\
\hline Atrativos & 0,045 \\
\hline & $\begin{array}{l}\mathrm{Q}^{2}>0 \\
\text { Modelo possui } \\
\text { validade preditiva }\end{array}$ \\
\hline
\end{tabular}

Fonte: Dados da Pesquisa (2019).

O indicador de Stone-Geisser avalia a capacidade preditiva do modelo ou relevância preditiva, onde valores acima de 0 indicam que existe relevância preditiva para um construto dependente particular (HAIR et al., 2016). Os valores da Tabela 8 para os construtos dependentes (Atendimento $=>0,208$ e Atrativos $=>0,045$ ) indicam que possuem validade preditiva.

A validação final foi feita por intermédio da análise dos caminhos do teste T de Student, por meio da análise Bootstrapping, conforme Tabela 9. 
Tur., Visão e Ação, v22, n3, p463-484, Set./Dez. 2020 - Balneário Camboriú, Santa Catarina, Brasil

Tabela 9 - Análise Bootstraping dos Caminhos

\begin{tabular}{|l|c|c|c|c|c|}
\hline & $\begin{array}{c}\text { Amostra } \\
\text { Original (O) }\end{array}$ & $\begin{array}{c}\text { Média } \\
\text { Amostral (M) }\end{array}$ & $\begin{array}{c}\text { Desvio } \\
\text { Padrão } \\
\text { (STDEV) }\end{array}$ & $\begin{array}{c}\text { Estatística T (O/ } \\
\text { STDEV) }\end{array}$ & P Valores \\
\hline Atendimento -> Atrativos & 0,051 & 0,050 & 0,069 & 0,735 & 0,463 \\
\hline Bem-Estar -> Atendimento & 0,555 & 0,554 & 0,033 & 16,799 & 0,000 \\
\hline Bem-Estar -> Atrativos & 0,145 & 0,145 & 0,064 & 2,252 & 0,025 \\
\hline Higiene -> Atendimento & 0,182 & 0,184 & 0,041 & 4,384 & 0,000 \\
\hline Higiene -> Atrativos & 0,115 & 0,118 & 0,057 & 2,032 & 0,043 \\
\hline Higiene -> Bem-Estar & 0,359 & 0,360 & 0,037 & 9,602 & 0,000 \\
\hline Low-cost -> Atendimento & 0,051 & 0,051 & 0,030 & 1,691 & 0,091 \\
\hline Low-cost -> Atrativos & 0,036 & 0,036 & 0,043 & 0,826 & 0,409 \\
\hline Low-cost -> Bem-Estar & 0,246 & 0,246 & 0,035 & 6,929 & 0,000 \\
\hline
\end{tabular}

Fonte: Dados da Pesquisa (2019).

A Tabela 9 demonstra que não existem caminhos para $\mathrm{H} 4=$ Atendimento $=>$ Atrativos $(\rho=0,463 ; \mathrm{T}=0,735), \mathrm{H} 1 \mathrm{~b}=$ Low-Cost $=>$ Atendimento $(\rho=0,091, \mathrm{~T}=1,691), \mathrm{H} 1 \mathrm{a}=$ Low-Cost => Atrativos $(\rho=0,826, T=0,409)$, o que leva à rejeição das hipóteses $\mathrm{Hla}, \mathrm{H} 1 \mathrm{~b}$ e H4, pois não foram suportadas.

A Tabela 9 demonstra que existem caminhos para Hlc - Low-Cost => Bem-Estar ( $\rho \leq 0,0001, \mathrm{~T}=6,929)$; $\mathrm{H} 2 \mathrm{a}-$ Bem-Estar => Atrativos $(\rho=0,025, \mathrm{~T}=2,252) ; \mathrm{H} 2 \mathrm{~b}-$ Bem-Estar $=>$ Atendimento $(\rho \leq 0,0001, T=16,799) ; \mathrm{H} 3 \mathrm{a}$ - Higiene => Bem-Estar $(\rho \leq 0,0001, \mathrm{~T}=9,602)$; H3b Higiene $=>$ Atrativos $(\rho=0,043, \mathrm{~T}=2,032) ; \mathrm{H3} \mathrm{c}$ - Higiene $=>$ Atendimento $(\rho \leq 0,0001, \mathrm{~T}=4,384)$.

Na Tabela 10 constam as hipóteses suportadas e não suportadas.

Tabela 10 - Hipóteses aceitas e não aceitas no modelo

\begin{tabular}{|c|l|c|}
\hline Hipóteses & \multicolumn{1}{|c|}{ Hipóteses Formuladas } & Situação \\
\hline Hla & $\begin{array}{l}\text { A adoção de modelo Low-Cost pelas Companhias Aéreas influencia } \\
\text { positivamente nos Atrativos oferecidos. }\end{array}$ & $\begin{array}{c}\text { Não } \\
\text { Suportada }\end{array}$ \\
\hline $\mathrm{H} 1 \mathrm{~b}$ & $\begin{array}{l}\text { A adoção de modelo Low-Cost pelas Companhias Aéreas influencia } \\
\text { positivamente no Atendimento das empresas Aéreas. }\end{array}$ & $\begin{array}{c}\text { Não } \\
\text { Suportada }\end{array}$ \\
\hline $\mathrm{H} 1 \mathrm{C}$ & $\begin{array}{l}\text { A adoção de modelo Low-Cost pelas Companhias Aéreas influencia } \\
\text { negativamente no Bem-estar. }\end{array}$ & Suportada \\
\hline $\mathrm{H} 2 \mathrm{a}$ & $\begin{array}{l}\text { O Bem-Estar sentido pelos passageiros influencia positivamente nos } \\
\text { atrativos oferecidos pelas Companhias Aéreas. }\end{array}$ & Suportada \\
\hline $\mathrm{H} 2 \mathrm{~b}$ & $\begin{array}{l}\text { O Bem-Estar percebido pelos passageiros influencia positivamente na } \\
\text { percepção do atendimento oferecido pelas Companhias Aéreas. }\end{array}$ & Suportada \\
\hline $\mathrm{H} 3 a$ & $\begin{array}{l}\text { A Higiene influencia positivamente na percepção de Bem-Estar dos } \\
\text { passageiros. }\end{array}$ & Suportada \\
\hline $\mathrm{H} 3 b$ & $\begin{array}{l}\text { A Higiene influencia positivamente na percepção dos atrativos oferecidos } \\
\text { pela Companhia Aérea. }\end{array}$ & Suportada \\
\hline $\mathrm{H} 3 \mathrm{c}$ & $\begin{array}{l}\text { A Higiene influencia positivamente na percepção de atendimento } \\
\text { oferecido pela Companhia Aérea. }\end{array}$ & Suportada \\
\hline $\mathrm{H} 4$ & $\begin{array}{l}\text { Oatendimento oferecido pela Companhia Aérea influencia positivamente } \\
\text { nos atrativos. }\end{array}$ & $\begin{array}{l}\text { Não } \\
\text { Suportada }\end{array}$ \\
\hline
\end{tabular}

Fonte: Dados da Pesquisa (2019). 
O Modelo final proporcionado pela validação das hipóteses geradas é demonstrado por meio da Figura 2, que será denominado Modelo LBAAH, que constitui o acrônimo para Low-Cost, Bem-Estar, Atrativos, Atendimento e Higiene, cujos resultados passarão a ser comentados a partir deste momento.

Figura 2 - Modelo Final LBAAH

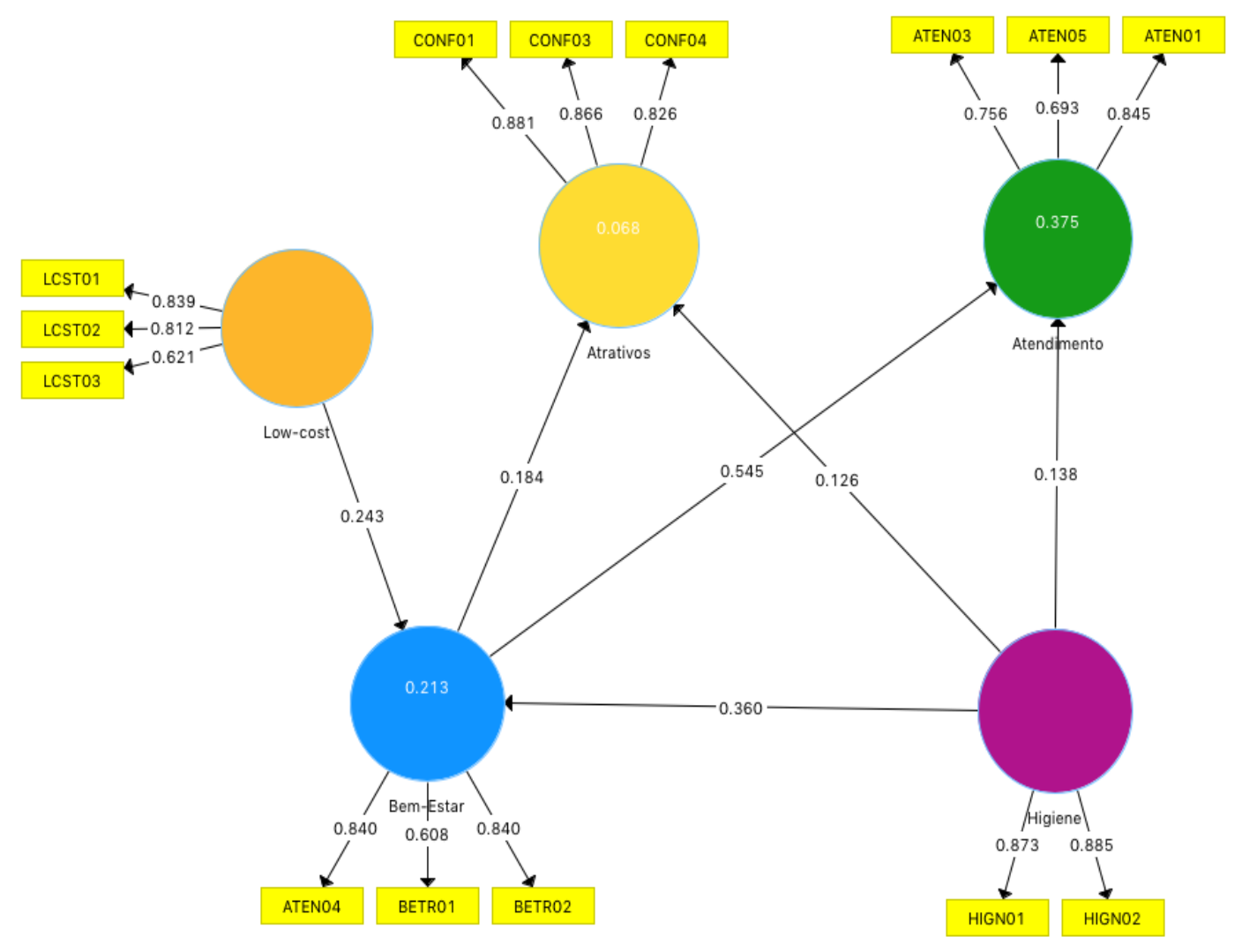

Fonte: Dados da Pesquisa (2019).

Hipótese Hla - A adoção do modelo "low-cost" pelas companhias aéreas influencia positivamente nos "atrativos" oferecidos (não suportada).

A interpretação literal deste resultado é que o modelo "low-cost" na aviação doméstica brasileira não funciona como um fator de atratividade.

Segundo Doganis (2006), este tipo de operação colocou as empresas tradicionais sob pressão especialmente nas viagens de curta e média distância. Segundo o autor, o desenvolvimento das empresas "low-cost" se deu em função da existência de significativas vantagens competitivas, tais como uso de aeroportos secundários, restrição de bagagens, frotas uniformizadas e adoção de medidas que geram redução de custos operacionais e não operacionais, influenciando em muitos aspectos da experiência de viagem, incluindo o conforto.

No mesmo contexto, Botelho (2017) acredita que o modelo "low-cost" está se esgotando, tendo em conta que as empresas já descobriram que poderão perder vendas se não devolverem um pouco do conforto de outrora. 
Portanto, a análise fatorial confirmatória está em consonância com a literatura, a pesquisa de campo e as impressões gerais dos autores ao não suportar esta hipótese no âmbito da aviação doméstica brasileira.

Hipótese Hib - A adoção de modelo "low-cost" pelas Companhias Aéreas influencia positivamente no "atendimento" das empresas aéreas (não suportada).

Conforme apresentado na hipótese $\mathrm{Hla}$, o modelo "low-cost" está associado a uma série de eventos que objetivam cortar custos com a finalidade de oferecer passagens aéreas mais baratas, no entanto, conforme constatado na análise fatorial exploratória, os passageiros não reconhecem a existência de empresas legitimamente "low-cost/low-fare" no Brasil, haja vista que os cortes de custos e a diminuição do conforto a bordo não são reconhecidos como fatores que implicam redução dos valores das passagens aéreas.

Assim, no momento em que a análise fatorial confirmatória constata que esta hipótese não é suportada, tal fato está em consonância com Doganis (2006), ao lembrar que as políticas de "low-cost" exercem influência em muitos aspectos da experiência de viagem, incluindo o conforto.

Hipótese HlC - A adoção de modelo "low-cost" pelas Companhias Aéreas influencia negativamente no "bem-estar" (suportada).

Os usuários do modelo "low-cost/low-fare" ao redor do mundo sabem o que vão encontrar ao adquirir um bilhete em uma empresa "low-cost/low-fare". Existe uma troca consentida na qual o passageiro sabe que realizará uma viagem espartana e como consequência pagará um valor médio abaixo do praticado pelas empresas tradicionais, sujeitando-se a uma menor franquia de bagagens, muitas vezes em horários diferenciados, sem o serviço de bordo gratuito e operando normalmente em aeroportos secundários.

Portanto a análise fatorial confirmatória, ao suportar a hipótese de que o modelo "low-cost" influencia negativamente no "bem-estar", está plenamente justificada pela revisão bibliográfica e pelo senso comum de que, ao se adquirir um bilhete "low-cost", os níveis de conforto serão menores.

Hipótese H2a - O "bem-estar" sentido pelos passageiros influencia positivamente nos "atrativos" oferecidos pelas Companhias Aéreas (suportada).

Neste caso, a análise fatorial confirmou a hipótese de que uma experiência prazerosa durante o voo, no que diz respeito ao "bem-estar", definido como a soma de aspectos tangíveis e intangíveis que permitem que o passageiro realize a viagem de forma confortável, exercerá influência positiva no passageiro no sentido de que ele se sinta motivado a voar novamente com a empresa.

Nesse sentido, vale a pena relembrar a fala de Kakinoff (2019) ao enfatizar que a hospitalidade pode não ser o fator isolado de escolha de uma companhia aérea, mas a falta de hospitalidade é o fator de abandono ou de rejeição de uma companhia aérea. Um cliente dificilmente esquece um mau atendimento a bordo e, se esquecer, leva alguns anos, porque mau atendimento a bordo normalmente está associado a uma necessidade que o cliente tem. 
Ressaltando a importância desse "bem-estar" sentido pelo passageiro, Camargo (2004) enfatiza que a hospitalidade se origina do sistema da dádiva e que ambas não são observáveis de maneira clara pelas ciências aplicadas, que têm por objetivo a gestão e quando percebida na sua dimensão de acolhimento, a hospitalidade revelase como uma espécie de vantagem competitiva para a empresa aérea.

Portanto, constata-se que a análise fatorial, ao confirmar esta hipótese, apenas corrobora a segunda hipótese qualitativa; o quanto descrito na revisão bibliográfica; os dados obtidos na coleta de campo; as informações fornecidas pelo Presidente da GOL e as impressões gerais do autor.

Hipótese H2b - 0 "bem-estar" percebido pelos passageiros influencia positivamente na percepção do "atendimento" oferecido pelas companhias aéreas (suportada).

O fator "bem-estar" foi definido como uma mescla de aspectos tangíveis e intangíveis que permitem que o passageiro realize a viagem de forma confortável. Já o fator "atendimento" está relacionado à qualidade das relações interpessoais entre passageiros e tripulantes. Desta forma, no momento em que a análise fatorial suporta esta correlação, constata-se que, se houver qualidade nas relações interpessoais, ou seja, o passageiro que se sentir acolhido, recebendo a atenção dos tripulantes necessariamente, tenderá a maximizar a sua percepção de "bem-estar".

Pode-se até dizer que no binômio "bem-estar/atendimento" repousariam dois alicerces da hospitalidade, pois, na visão de Grinover (2002), a palavra hospitalidade pode ser entendida como recepção de hóspedes, visitantes e viajantes, podendo ser simplificada no ato de bem receber. De posse desse dado, leva-se a acreditar que a associação dos aspectos intangíveis (sorriso, simpatia, calor humano, atenção, educação, delicadeza) aos aspectos tangíveis (assentos confortáveis, bom serviço de bordo, temperatura adequada, pontualidade) provavelmente formariam o cenário ideal para se acolher os passageiros. Também nesse sentido Kakinoff (2019) apresenta o que chamou de mantra para todos os funcionários que interagem com os passageiros, que consiste no trinômio segurança, simplicidade e simpatia, englobando, neste caso, fatores tangíveis e principalmente os intangíveis, resultado da qualidade das relações interpessoais.

Hipótese H3a - A "higiene" influencia positivamente na percepção de "bemestar" dos passageiros (suportada).

Ao suportar esta hipótese, a análise fatorial indica que o fator "bem-estar" definido como o conjunto de aspectos tangíveis e intangíveis que permitem que o passageiro realize a viagem de forma confortável é influenciado positivamente pela "higiene" percebida a bordo da aeronave.

Assim, para se reconhecer a importância da "higiene", se resgata a definição de Nameghi e Ariffin (2013) para a dimensão conforto, que está relacionada tanto a fatores tangíveis relacionados à qualidade da infraestrutura e das facilidades disponibilizadas a bordo, bem como ao conforto psicológico que trará a tranquilidade e a confiança necessárias ao "bem-estar" do passageiro durante a viagem. 
Desta forma, o fator "higiene" será um dos componentes que propiciará o "bem-estar" que todos os passageiros esperam e a empresa se esforça em promover. Corroborando essa ideia, Botelho (2017) acrescenta que empresas fora do Brasil têm apresentado novidades para agradar os passageiros, dentre elas, a higienização dos banheiros das aeronaves, em apenas três segundos, por meio de luz ultravioleta.

Portanto, fica clara a confirmação da hipótese ao associar positivamente o fator "higiene" ao fator "bem-estar", tendo em vista que juntos conduzirão à sensação geral de conforto almejada por todas as empresas aéreas.

Hipótese H3b - A higiene influencia positivamente na percepção dos atrativos oferecidos pela empresa aérea (suportada).

O fator "atrativos" foi definido pelos autores como um conjunto de motivos que levam o passageiro a fazer a escolha pela empresa aérea. Assim, a análise fatorial, nesta hipótese, confirma que a higiene atua positivamente nos complexos meandros que levam um passageiro a optar por uma empresa aérea em detrimento de outra.

Tal constatação pode ser identificada em Kakinoff (2019) ao explicar que, na percepção do cliente, o avião deveria funcionar como uma grande máquina do tempo, na qual o passageiro entra no avião, fica entretido, dorme, descansa, trabalha e não percebe que viajou. Assim, terá sido prestado o melhor serviço se o passageiro não perceber que voou. Portanto, para que o passageiro sinta essa continuidade de sua vida sem se dar conta da realização do voo é importante que este ambiente esteja adequadamente higienizado, pois, do contrário, a sensação de rejeição ao ambiente e de desconforto é imediata.

Hipótese H3c-A higiene influencia positivamente na percepção de atendimento oferecido pela empresa aérea (suportada).

Cabe lembrar que o fator "atendimento" está relacionado à qualidade das relações interpessoais entre passageiros e tripulantes, restando a pergunta de por qual motivo um fator tangível, como é o caso da "higiene", influencia positivamente na percepção da qualidade das relações interpessoais.

A resposta é simples e cada um se colocando na posição de um passageiro chegaria facilmente a esta conclusão. Observando-se a Figura 1 (Modelo Teórico de Correlações), percebe-se que assim como a "higiene" influencia no "atendimento" (hipótese 3c), a "higiene" também influencia no "bem-estar" (hipótese 3a) e, por conseguinte, o "bem-estar" influencia no "atendimento" (hipótese 2b). Assim, estes três fatores estão inter-relacionados. Basta imaginar a cena de um passageiro embarcando em uma aeronave suja, em que, por mais gentileza e acolhimento que a tripulação prestasse, dificilmente se reverteria o mal-estar.

Portanto, o que se conclui é que, se a pessoa estiver em um ambiente perfeitamente higienizado, se aumentará a sensação de "bem-estar", permitindo que as relações interpessoais ocorram com melhor qualidade.

Hipótese H4 - O atendimento oferecido pela Companhia Aérea influencia positivamente nos "atrativos" (não suportada). 
Ao constatar que a análise fatorial não suportou este comportamento, procurouse, no universo da revisão bibliográfica, os motivos pelos quais o fator "atendimento" não exerceria influência positiva no fator "atrativos". Inicialmente, a não confirmação desta hipótese causou inquietação. Cabe, no entanto, esclarecer que esta inquietação foi superada ao se imaginar o que o passageiro esperaria encontrar a bordo da aeronave. A resposta surgiu como uma imagem gravada na mente, de anos de utilização do transporte aéreo doméstico brasileiro, no qual a primeira visão na porta de entrada da aeronave é uma comissária recebendo os passageiros com um sorriso nos lábios, apresentando as boas-vindas da tripulação. Ou seja, este comportamento é o esperado pelos passageiros, portanto não se concebe que essa cena se desenvolva de forma diferente. Na entrevista com Kakinoff (2019), ao ser questionado quanto à importância da hospitalidade a bordo das aeronaves, este respondeu que a hospitalidade pode não ser o fator isolado de escolha de uma companhia aérea, mas certamente a falta de hospitalidade é o fator de abandono ou de rejeição de uma companhia aérea.

Finalmente, tal comportamento pode estar associado ao que Herzberg (1987) usou chamar de fatores higiênicos, que são considerados componentes esperados, que seriam quase uma obrigação, sendo que ao não se materializarem, tornam-se motivo de grande insatisfação.

\section{CONSIDERAÇÕES FINAIS}

Ao se finalizar este estudo, percebe-se a sua importância ao juntar dois universos importantes, quais sejam, da hospitalidade e da aviação que, como visto na revisão bibliográfica, ainda não têm uma gama variada de pesquisas. O ponto a se ressaltar foi a apresentação da hospitalidade a bordo das aeronaves a partir da visão dos passageiros, ressaltando-se como pontos principais as seguintes constatações:

- os passageiros não reconhecem a existência de empresas legitimamente "lowcost/low-fare" no Brasil, pois os cortes de custos e a diminuição do conforto a bordo não são reconhecidos como fatores que implicam em redução dos valores das passagens aéreas;

- a adoção do modelo "low-cost" traz atrelada a sensação de que o fator "atendimento" será aquém do prestado em uma empresa de modelo tradicional;

- uma experiência prazerosa durante o voo, no que diz respeito ao "bem-estar", exercerá influência positiva no passageiro no sentido de que ele se sinta motivado a voar novamente com a empresa; e

- se houver qualidade nas relações interpessoais, o passageiro tenderá a maximizar a sua percepção de "bem-estar".

Desta forma, está alcançado o objetivo geral desta pesquisa, que foi enxergar a forma como os passageiros enxergam a hospitalidade a bordo das aeronaves do transporte aéreo doméstico brasileiro.

No que se referem às limitações da pesquisa, os resultados são válidos para a realidade do mercado da aviação doméstica brasileira, não podendo essas conclusões 
ser generalizadas, por exemplo, para os voos internacionais de empresas brasileiras ou para o cenário de outros países. Em relação às pesquisas futuras, sugere-se aplicar o presente instrumento de pesquisa em outros países, fazendo-se assim um comparativo entre a realidade da aviação doméstica brasileira e a do país objeto do novo estudo.

\section{REFERÊNCIAS BIBLIOGRÁFICAS}

Archana, R. \& Shuba, Dr. M. V. (2012) A study on service quality and passenger satisfaction on indian airlines. International Journal of Multidisciplinary Research. Vol.2. Issue 2, February 2012, ISSN 2231 5780. Disponível em: http://www.prosperfinancialmanagement.com/assets/client_files/PDFs/ jd.pdf, acessado em 15/06/2019.

Botelho, T. (2017) Voar é Humano. São Paulo: Revista Veja, nº 2512.

Calçada J. R. M. (2018) A hospitalidade percebida pelos tripulantes do CAN no atendimento às populações isoladas da Amazônia. Dissertação (Mestrado em Hospitalidade). Universidade Anhembi Morumbi, São Paulo. Disponível em: https://portal.anhembi.br/wp-content/ uploads/2018/12/disserta\%C3\% A7\%C3\% A3O_ROBERTO-MOREIRA-CAL\%C3\%87ADA-JUNIOR. pdf, acessado em 15/06/2019.

Camargo, L. O. L. (2004) Hospitalidade. São Paulo: Aleph.

Camargo, L. O. L. (2015) Os interstícios da hospitalidade. Revista Hospitalidade. São Paulo, v. XII, n. especial, p. 42-69, maio, 2015. Disponível em: https://www.revhosp.org/hospitalidade/article/ view/574, acessado em 15/06/2019.

Chang, H. \& Yang, C. (2008) Explore airlines' brand niches through measuring passengers' repurchase motivation-an application of Rasch measurement. Journal of Air Transport Management 14 - 05112. Disponível em: https://doi.org/10.1016/j.jairtraman.2008.02.004, acessado em 15/06/2019.

Chin, W. W. \& Henseler, J.; Wang, H. (2016) Handbook of Partial Least Squares. S.I.: Springer.

Creswell, J., W. (2010) Projeto de pesquisa: métodos qualitativo, quantitativo e misto. Tradução Magda Lopes; consultoria, supervisão e revisão técnica Dirceu da Silva. 3 ed. Porto Alegre: Artmed.

Doganis, R. (2002) Flying off Course: the economics of international airlines. Londres: Routledge.

Faizan A., Bidit L. D. \& Raffaele F. (2015) "An assessment of service quality and resulting customer satisfaction in Pakistan International Airlines: Findings from foreigners and overseas Pakistani customers". International Journal of Quality \& Reliability Management, Vol. 32 Issue: 5, pp.486502, Disponível em: https://doi.org/10.1108/IJQRM-07-2013-0110, acessado em 15/06/2019.

Favorito, F. (2013) Avaliação do Setor de Serviços do Aeroporto de Congonhas. Dissertação (Mestrado em Hospitalidade). Universidade Anhembi Morumbi, São Paulo. Disponível em: http://www. univates.br/revistas/index.php/estudoe debate/article/view/606, acessado em 15/06/2019.

Félix, G. R. A. (2006) Educação Corporativa: Estudo de caso em uma empresa de transporte aéreo. Dissertação (Mestrado em Hospitalidade). Universidade Anhembi Morumbi, São Paulo. Disponível em: http://livros01.livrosgratis.com.br/cp009882.pdf, acessado em 15/06/2019. 
Fornell, C. \& Larcker, D. F. (1981) Structural Equation Models with Unobservable Variables and Measurement Error: Algebra and Statistics. Journal of Marketing Research, v. 18, n. 3, p. 382-388.

Garson, G. D. (2016) Partial Least Squares Regression and Structural Equation Models: 2016 Edition (Statistical Associates Blue Book Series 10). [S.I.]: Statistical Associates Publishers.

Gil, A. C. (2010) Como elaborar projetos de pesquisa. 5. ed. São Paulo: Atlas.

Goldenberg, C. (2016) Mobilidade corporativa, relações de hospitalidade entre stakeholders e a nova classe média: um estudo de casos múltiplos. Dissertação (Mestrado em Hospitalidade). Universidade Anhembi Morumbi, São Paulo. Disponível em https://portal.anhembi.br/wpcontent/uploads/2017/06/ Dissertacao_CINTIA-GOLDENBERG.pdf, acessado em 05/07/2019.

Gotman, A. (2001) Le sens de I'hospitalité. Paris: Presses Universitaires de France.

Grinover, L. (2002) Hospitalidade: um tema a ser reestudado e pesquisado. In: DIAS, Célia M. (Org.). Hospitalidade: reflexões e perspectivas. São Paulo: Manole.

Hair, J. F. et al. (2009) Análise Multivariada de Dados. Edição: 6a ed. [s.I.] Bookman.

Henseler, J., Ringle C. \& R. Sinkovics, R. (2009) The Use of Partial Least Squares Path Modeling in International Marketing. [S.I: s.n.], v. 20.

Herzberg, F. (1987) One More Time: How Do You Motivate Employees? Harwards Business, Review, September-October, 1-16.

Hu, L. \& Bentler, P. M. (1999) Cutoff criteria for fit indexes in covariance structure analysis: Conventional criteria versus new alternatives. Structural Equation Modeling: A Multidisciplinary Journal, v. 6, n. 1, p. 1-55, 1 jan. 1999.

Kakinoff, P. S. (2019) Paulo Sérgio Kakinoff: entrevista. São Paulo, 1 arquivo .mp3 (25':18' ').

Kaperaviczus, A. F. (2015) A Evolução da Hospitalidade na Aviação: do voo do "Jahú" aos tempos atuais de competição entre empresas tradicionais e "low-cost". Dissertação (Mestrado em Hospitalidade). Universidade Anhembi Morumbi, São Paulo. Disponível em: http://docplayer. com.br/15994162-Universidade-anhembi-morumbi-alexandre-faro-kaperaviczus.html, acessado em 15/06/2019.

Massarat, G. \& Jha, S. (2014) Assessing Customer Perception of Service Quality: Comparative Study of Airlines in UAE. World Review of Business Research Vol. 4. No. 2. July 2014 Issue. Pp. 291 - 303. Disponivel em: https://pdfs.semanticscholar.org/855d/117fe4bc239712f4fde8d01f08809f8284fd. pdf, acessado em 15/06/2019.

Motiani, S., Patil, J. \& Borkar, S. (2013) Role and Scope of hospitality in aviation. International Journal of Commerce and Business Management. Volume 6, Issue 1, April

Nameghi, E. N. M. (2013) The Relationship between Private Domain and Commercial Domain of Hospitality in Airlines: Employing Partial Least Square Technique. International Journal of Marketing Studies. Vol. 5, No. 2; 2013. ISSN 1918-719X. Disponível em: http://www.ccsenet.org/journal/index.php/ijms/ article/ view/22330, acessado em 15/06/2019.

Nameghi, E. N. M. \& Ariffin, A. A. M. (2013) The measurement scale for airline hospitality: Cabin crew's performance perspective. Journal of Air Transport Management. Disponível em: http://www. sciencedirect.com/science/article/pii/ S096969971300032X, acessado em 15/06/2019. 
Tur., Visão e Ação, v22, n3, p463-484, Set./Dez. 2020 - Balneário Camboriú, Santa Catarina, Brasil

Nejati, M., Nejati, M. \& Shafaei, A. (2009). Ranking airlines' service quality factors using a fuzzy approach: study of the Iranian society. International Journal of Quality \& Reliability Management, Vol. 26 Issue: 3, pp.247-260, Disponível em: https://doi.org/10.1108/02656710910936726, acessado em $15 / 06 / 2019$.

Nilsson, J. H. (2012) Hospitality in Aviation: A genealogical study. Hospitality \& Society Journal 2:1, p 77-98. Disponível em: https://www.ingentaconnect.com/content/ intellect/ hosp/2012/00000002/00000001/art00005, acessado em 15/06/2019.

Pestana, M. H. \& Gageiro, J. N. (2013) Análise de Dados para as Ciências Sociais-A Complementariedade do SPSS - 5. Ed. Lisboa: ND-EDIÇÕES SILABO.

Salva, V. (2017) A Gestão de Serviços em Hospitalidade: O papel do comissário como anfitrião nas empresas aéreas comerciais brasileiras. Dissertação (Mestrado em Hospitalidade). Universidade Anhembi Morumbi, São Paulo. Disponível em: https://www.anptur.org.br/anais/anais/files/13/437. pdf, acessado em 15/06/2019.

Sampieri, R. H., Collado, C. F. \& Lucio, M. del P. B. (2013) Metodologia de Pesquisa. Tradução: Daisy Vaz de Moraes; revisão técnica: Ana Gracinda Queluz Garcia, Dirceu da Silva, Marcos Julio. 5. ed. Porto Alegre: Penso.

Santos, A. J. N. (2017) Hospitalidade e Serviços a Bordo de Aeronaves: o caso da Azul Linhas Aéreas. Dissertação (Mestrado em Hospitalidade). Universidade Anhembi Morumbi, São Paulo. Disponível em: http://bdtd.ibict.br/vufind/ Record/ANHE_b3445679efa4ae8dfaaea02579ce0dbl, acessado em 15/06/2019.

Suki, N. M. (2014) Passenger satisfaction with airline service quality in Malaysia: A structural equation modeling approach. Research in Transportation Business \& Management 10 (2014) 26-32. Disponível em: https://www.sciencedirect.com/ science/article/pii/S2210539514000108, acessado em 15/06/2019.

Yeoh, E. \& Chan, J. K. L. (2011) Malaysian Low Cost Airlines: Key influencing Factors on Customers' Repeat Purchase Intention. World Applied Sciences Journal 12 (Special Issue of Tourism \& Hospitality): 35-43, 2011. Disponível em: https://pdfs.semanticscholar.org/fdcc/ ba37d9a357832e144d15c668ea771 1adb337.pdf, acessado em 15/06/2019.

Contribuição de cada autor na construção do artigo

Alexandre Faro Kaperaviczus: Preparação do referencial teórico, Coleta de Dados, Análise dos Dados, Elaboração do Relatório de Pesquisa.

Airton José Cavenaghi: Avaliação do referencial teórico, Análise dos dados, Elaboração e avaliação do Relatório de Pesquisa.

Paulo Sérgio Gonçalves de Oliveira: Análise dos Dados, Elaboração do Referencial Teórico, Modelagem Estatística. 